\title{
Light as a Medium for Supporting Leisure Activities in Open Public Spaces
}

\author{
Ivana RAKONJAC*, Ivan RAKONJAC, Ana ZORIĆ, Vladan DJOKIĆ, Milica P. MILOJEVIĆ, Milena RAJIĆ
}

\begin{abstract}
This work identifies lighting as a non-invasive method for the transformation of a space that simultaneously and unconstructively articulates various activities and does not interfere with the inherited physical framework. Through experimental research and a case study of the "Eastern City Gate of Belgrade" housing settlement in Serbia, which was designed and built in the second half of the 20th century, the activity rhythm of a contemporary user is explored. The research goal was to recognise the decision-making tools for increasing the quality of open public spaces during the night-time mode of use by improving the quality of lighting. The study proposes the new lighting design model that supports night-time leisure activities in mass housing open public spaces in the contemporary urban context.
\end{abstract}

Keywords: artificial night light; lighting design; night-time activities; recreational activities; safety; urban design

\section{INTRODUCTION}

The significance of lighting in the urban design is designated by the relation of the users and environment through the experience of architectural and ambiance values of the space. The basic role of the lighting in an open public space is to enable an agreeable ambiance and the desired visual experience; to enable outdoor activities; to offer safeness, security, but also to emphasise the aesthetic and symbolic values of the space. The changes in contemporary lifestyle impact the rhythm of outdoor activities in an urban context. This transformation is common in the spaces designed under the socialist paradigm and modernist principles. Former community spaces in mass housing modernist settlements represent specific open public spaces on which recreational dimension is an important parameter of sustainable active space. Climate changes brought high temperatures during the day; hence the night-time period became more suitable for outdoor activities. Furthermore, influenced by global culture, the position of leisure activities in contemporary lifestyle is shifted to night-time hours.

Previous lighting design in modernist mass housing settlements focuses on the functional aspect of lighting design: movement orientation and small social gatherings of residents, while the green areas and surroundings structure remain neglected. This lighting design approach is designated by the modernist lifestyle which puts the recreational dimension in day-time activities. In these settlements, the appearance of unlit areas creates the feeling of unsafe location, which does not permit the development of leisure activities in the night-time period.

The purpose of this paper is to highlight the significance of lighting design for supporting leisure activities in open public spaces in residential settlements. The specific focus of this research is on the contribution of lighting for visitors' interest in open public space within the housing settlements designated with symbolic values. The main goal is to propose a new lighting design model for supporting night-time leisure activities in mass housing open public spaces. The research hypothesis investigates relations of lighting quality and leisure activities from the aspects of the spatial, program and symbolic features of open public space. A starting point of presented research are questions: (1) how light can contribute to the development of the recreational dimensions of open public spaces and (2) how to provide lighting quality that supports leisure activities in the night-time period? Through an exploratory case study, the influence of lighting quality on the recreational activities' rhythm of a contemporary user is tested. By operationalisation of the proposed lighting design model for supporting nighttime leisure activities in mass housing open spaces, the efficiency is tested through the scenario of light quality improvement. This way, the practical application of the model can be achieved.

\section{PREVIOUS RESEARCH AND THEORETICAL FRAMEWORK}

Influenced by global cultural trends, the lifestyle is constantly changing. As a part of history pertaining to all nations under the influence of the socialist paradigm, the topic of transformation open public is slowly beginning to attract the attention of researchers from countries with similar backgrounds who aim to explore the social, cultural and economic aspects of these spaces, as well as the problems of their functionality, degradation and abandonment [1-3]. The transformation of modernist urban spaces has produced urban fragmentation, reflected through the decentralisation of housing and socio-spatial stratification which is becoming a frequent research topic in the context of sustainability. These transformations of cities are often characterised by a significant reduction and conversion of green areas into other contents such as in Slovakia [2] as well as fragmentation of open public spaces in Bulgaria [4], which encourages research on environmental sustainability in modern conditions. On the other hand, in the cities of Russia and Poland, there is privatisation and commercialisation of open public areas $[1,2]$, which produces chaotic expansion of urban areas, which encourages social divisions and problematises social sustainability. Existing research in the field of postsocialist city transformation has mostly dealt with the topics of individual, iconic buildings and has not paid sufficient attention to urban design, especially the public spaces of the modernist city scape and housing spaces. The previous research works present how planned activities can be initiated by determining their content. The topic of transformation of modernist urban areas is not sufficiently addressed from the aspect of lighting, especially when it comes to open public space and recreational dimension. 


\subsection{Contemporary Cultural Changes and Recreation}

The cultural aspect articulates that the exchange of information in a space defines the level of the associative quality of content and regulates the method of interaction between the users and the environment [5]. The change in cultural trends in the contemporary context has caused changes in the understanding of people's way of life and, therefore, their attitude toward space. Mass culture, as a facet of the socialist paradigm, has envisioned and occupied working and free time through the system of organised behaviour popularised by spaces and products [6]. The importance of the community and the aspiration to cultivate this phenomenon were established by creating the community spaces and universal content as a manifestation of uniform needs and planned activities. As opposed to that, the contemporary context is based on a cosmopolitan attitude to life, where the city represents a ground for expressing individual free will and a community acts as a body of individuals [7]. Nowadays, lifestyle is characterised by the non-regulated consumption of time, which leads to its fragmentation. The leisure activities sidelined by work increasingly shift toward night hours.

At the level of neighbourhood activities, the key difference stems from the change in the concept of housing from collective to multifamily, which defines the quantity and omits the character of relations between the elements of the settlement dwelling entity [8]. The changes in users' practices and needs are visible today through the different interpretations of free time during the post-socialist period, prompting changes in the users' relationship to space and its use. This change came as a consequence of sociocultural exchange between the local and global experiences and interpretations. Recognising the evident spontaneous transformation of these spaces (casual appropriation, new activities and modes of use), from the aspect of Lefebvre's concept of space production [9], this fact also represents the potential for their adaptation to contemporary circumstances by using methods which could enable the unhindered and safe articulation of new activities, but also the preservation of the built structures' heritage values. Namely, in spontaneously developed user activities (sports, cultural activities, board games, relaxation and creative activities), Lefebvre recognises various forms of gathering within space, as modern spatial formations adaptable to all. Relying on this concept, the basic premise of the research is that the contemporary form of life of former community spaces is enabled by supporting these activities through urban design.

Life in a modern city today is a complex process which requires completely new dimensions of perception that are aimed at understanding the everyday life of users in order to provide a modern, healthy and high-quality life while preserving the character and identity of the inherited urban structure [10]. The contemporary way of life, characterised by a free choice regarding the rhythm of life, activities and content, alters the nature of free time. Contrary to the clear time division present in the modernist society, the nature of today's free time has been transformed from a quantifiable and determined category into a fluid and undefined one whose fragments permeate everyday life. Contemporary life in a city, distinguished by the hyperproduction of products and spaces, which, in turn, causes the domination of job responsibilities, increases the need for free time as "a critique of everyday life" according to Lefebvre [11]. Namely, leisure activities, in addition to job and private responsibilities, represent, according to Lefebvre, the third crucial element of individual everyday life. The importance of this element is explained by the need to free ourselves from the routine of everyday activities. The unvarying rhythm and limited content in this case represent the tension that an individual seeks to overcome through freedom of choice regarding the mode and manner of organising their free time.

Contemporary research on sustainable urban development emphasises the importance of open public spaces in the context of recreation and leisure activities. The benefits of staying outdoors are recognisable in the promotion of physical health [12,13], as well as emotional and behavioural well-being [14]. On the other hand, the development of common activities stimulates social interaction, but also promotes learning about the environment by getting to know its contents and attractions [15]. In this sense, recreational activities in open public spaces help the population to connect with the cultural heritage and nurture identity $[12,16]$. The balance of these benefits in open public spaces helps long-term sociocultural reinforcement, which contributes to the whole community through the adequate articulation of open content. By improving the quality of open public spaces in the urban environment, the overall quality of citizens' lives is increased through the creation of a sense of community, civic identity and urban culture [5]. Accordingly, encouraging leisure activities in the open public spaces of socialist heritage also contributes to social sustainability.

\subsection{Lighting for Open Public Space}

Lighting contributes to promoting the identity of the place by emphasising the cultural and architectural heritage. Since adequate lighting is a perceptual condition and makes the architecture visible [17], but also safe and adequate for various functions [18], this research attends to present lighting design as a medium for supporting the recreational potential of community spaces and transforming them into the leisure spaces of today.

In the lighting design field, possibilities for improvement of the recreational dimension of open public spaces by lighting have not been investigated yet. Experience of space in a night-time period is conditioned by light influence on user-space relation.

Depending on the intensity of sensory experience, the distance between a user and different spatial elements is considered to be important and can be perceived as intimate, personal, social, or public [19]. Also, the speed of users' movement influences the perception of spatial characteristics [20]. While moving in a pedestrian zone, a user can perceive spatial characteristics even from a short distance. Walking, in comparison to other modes of movement (cycling and driving) is featured a more intimate relationship between the user and its surrounding, which enables more articulated interpretation and memorisation of the environment. Hence, the approach to defining qualitative aspects of light design within open public spaces intended for recreation is considered through the distance relation between a user and space. 
Speaking of intimate and personal distances, these relations are determined by small distances between the user and spatial elements, hence they can be recognised in indoor space. In the book Lighting in architecture: Requirements and guidelines for design [18], Djokić presented the wide scope of guidelines for lighting design in the field of architecture, dominantly in interior design, and considered six aspects of lighting quality: (1) bioaspect; (2) physical aspect; (3) functional aspect; (4) aspect of architectural style; (5) aspect of applied materials; and (6) aspect of applied colors. The necessity for space-time orientation is basic bio-aspect, while the perception of spatial characteristics (elements relations, their distances, spatial disposition) defines physical aspects of space. The aspect of architectural style is determined by the effect of light on the presentation of architectural values of the space itself, while aspects of applied materials and colors define light influence on the perception of elements featured in the space. The intimate relation between user and space, as well as visual tasks demands in indoor space, impose multiple light design requests.

On the other hand, social and public categories are determined by the greater distances of users and spatial elements. To clearely define lighting quality parametres in the open public space framework, it is necessary to take in consideration the current standards and recommendations for the lighting design in the complex urban realm of the city: IESNA (Illuminating Engineering Society of North America) [21], CIE (International Commission of Illumination) [22] and CEN (European Committee for Standardization) [23]. According to the standards and recommendations for open public pedestrian area, requests to lighting design are in the aspect of functional quality users' orientation, development of outdoor activities, safe and secure space.

These requirements are achieved by reaching an adequate level of illumination according to the space function and the pedestrian traffic frequency at night time - defined in three categories: very active (commercial zone), moderately active (intermediate zone), and little active space (residential zone) [21]. The influence of the luminocity of the surroundings, i.e. lighting from the neighbouring areas, is defined by three categories - high, moderate and low [22], or depending on the urban context - rural, urban and city center [23]. Furthermore, the lighting design is directed by the lighting technical class - for the various types of open public space, the types of lighting situations are defined [22, 23]. The lighting technical classes are determined by specific sets of parameters which are based on the category of the existing traffic in space, users' motion speed, and the roughly denoted dominant space function (program).

The open public pedestrian areas present the epicenter of public life in an urban context. The slower motion of users enables gathering, communication, and interaction. Hence, lighting should fulfill the users' requirements to orientate in space and feel safe and secure; to perform a planned activity; the accomplishment of the pleasant feeling and agreeable atmosphere; to experience the aesthetic and ambiance values of the space [20]. The artificial night light makes the urban environment more comfortable for users and visitors, providing the users' orientation and feeling of safety as essential requirements in an open public space [24]. For the perceptual dimension of space, the quality of the visual information is of great significance [25]. Light contributes to an adequate presentation of the image of a place.

Bearing in mind the relationship between users and space, the lighting design parameters for open public areas to support leisure activities has been suggested by the study. According to the presented theoretical context, the research systematises lighting quality parameters for open public spaces and pedestrian zones: (a) selection of the light source, luminaire type, optical features, and the physical arrangement (the quality parameter describes influence on light distribution); (b) illuminance level and overall uniformity (the quality parameter for the overall illuminance distribution); (c) light pollution (is the presence of unwanted, inappropriate, or excessive lighting); (d) the users' feeling of safe and secure space (the quality parameter based on basic orientation in space, perceiving obstacles and face recognition); and (e) the specific elements and points of interest (highlighting the key elements of the space). Furthermore, the lighting quality parameters application concerning the characteristics of open public space is proposed, following the basic aspects in the field of architectural design - (1) functional (program); (2) physical (structural) and symbolic (inherited) values.

\section{Functional lighting}

As previously pointed out, the functional aspect presents a primary requirement in lighting design for open public space. Fulfillment of basic orientation in space and provision of adequate illuminance to achieve a certain degree of safety, to discourage criminal activities so that the users feel safe and secure. Functional lighting enables uninterrupted anticipated outdoor activities, and lighting requirements are reflected in the adequate level of average horizontal illuminance and overall uniformity (on the ground level). Illuminance should comply to the standard defined minimal (up to $1 \mathrm{~lx}$ ) and average (up to $3 \mathrm{~lx}$ ) values for open public spaces within residential areas. For functional lighting, it is crucial to achieve quality light distribution within the space, which depends on the selected light source and optical features of the luminaire, as well as the physical arrangement (position, height, etc.). Thus, it is important to consider overall uniformity, which should not exceed a ratio of 1:4.

\section{Ambient lighting}

In addition to the functional aspect of lighting highlighted by existing recommendations snd standards, visibility of spatial characteristics and specific areas that present support for various outdoor activities is significant for affirmation of physical context. The purpose of lighting within open public spaces is reflected in the establishment of an inviting atmosphere and pleasant ambiance by achieving the desired level of user comfort. Ambient lighting enables the desired ambiance in line with the values the space has when illuminated by natural (sun) light but can also lead to the transformation of the ambiance during the night hours and result in the creation of a different atmosphere. The quality of ambient lighting depends on the selection of the luminaire type, light source power and temperature colour (CCT) number, shape, size and photometric characteristics of the luminaires applied. However, to achieve the desired effects, the arrangement 
of the luminaires in relation to spatial properties also plays an important role.

\section{Decorative architectural lighting}

Furthermore, supporting outdoor activities in open public spaces in night-time period is important to increase the desirability of the ambiance. Perceiving the impact of light on spatial experience is important to emphasise the identity of the place. To affirm the architectural and symbolic values of space, the role of decorative architectural lighting is to highlight the key elements of the built environment. The main task of decorative lighting is to accomplish appropriate levels of horizontal illuminance and a level of overall uniformity that would heighten the visibility of the relief and detailed shape of objects. Achieving the desired effects by using architectural lighting depends on the selection of the luminaire type, light source power and temperature colour number, shape, size and photometric characteristic of luminaries applied. Moreover, additional parameters that affect decorative lighting are the position and orientation in relation to the physical and functional properties of the space. Adequate lighting can take the attractiveness of an urban environment to the next level.

To support recreational outdoor activities in night-time period in modernist residential settlements, lighting design should meet the defined requirements from the mentioned aspects according to the three lighting types. Fulfillment of the functional aspect is reflected in the secure space for access to residential buildings and areas of open public space suitable for various activities. To provide a pleasant environment for the development of the leisure activities, it is necessary to achieve visual comfort by applying the parameters defined by the aspect of ambient lighting. For open public spaces that have iconic value for architectural heritage and the cityscape, it is important to highlight night-time appearance. Hence, to support city image and increase the ambiance desirability to various groups of visitors, the application of decorative architectural lightening in the design process is essential.

To define the correlation between lighting quality and leisure activities, the new lighting design model is proposed based on three types of architectural lighting.

The starting point of model establishment is to define recreational activities suitable for open public spaces in residential settlements in night-time hours. The main characteristic of these settlements is determined by requirements for pleasant ambiance which allows for privacy and comfort in the private area of residents. Limitation to outdoor activities that produce a high level of noise, primarily. Subsequently, a number of users gather to perform outdoor activities, and finally, the frequency of non-residents users disturbs the sense of security of the neighborhood. The recreational activities categoriced by these requirements/parameters define the necessity to constrain some outdoor activities in residential settlements. The limitation is presented in the engagement of different parameters (noise, number of users, frequency of nonresidents users) and leisure activities in night-time period constraining level: none - without need for suppression (walking, sitting, reading, running); low - very small impact of a number of users, frequency of non-resident users (board games, cycling); medium - the medium impact of the level of noise, number of users, frequency of non- residents users (exercising, skateboarding); high - the impact of the level of noise, number of users, frequency of non-resident users (sports, informal gatherings, forma lgatherings).

Second step in model establishment is to define relationship between leisure activities in night-time period and lighting quality. The existing recommendations and standards for lighting design are based on the user's movement speed and the possibility of perceiving the characteristics of the environment. Therefore, it is very important to categorise leisure activities according to this criterion. According to kinetic experience and dynamics of outdoor recreational activities, three categories are defined: (1) passive - do not require active movement (walking, sitting, reading, board games); (2) medium - slow movement (exercising, informal and formal gatherings); (3) dynamic - fast movement (cycling, skateboarding, and sports). The next step to finalise the model is to overlap recreational activities and limitations in mass housing settlements with lighting parameters. The new lighting design model that supports night-time leisure activities in mass housing open public spaces in the contemporary urban context, combining three parameters - outdoor recreational activities, open public space in a modernist residential settlement, and aspect of light quality is presented in Tab. 1.

To support the development of leisure activities in open public spaces in an urban context it is necessary to perceive limitations defined by program (functional) structure, spatial (physical), and symbolic features. Presented work intends to illuminate night-time outdoor activities decrease problems in open public space and its degradation as an effect of inadequate lighting. The proposed model suggests a non-invasive method of preserving active open public space in the night-time period aligned with contemporary uses' lifestyle.

\section{MATERIALS AND METHODS}

The paper uses several methods to develop a theoretical framework and create an outline for the exploratory case study and interpretation of the results. The theoretical framework of the research was developed as the literature review and content analysis of the relevant sources in the fields of urban and lighting design. The research was based on the identification of terms and categories relevant to our research to establish a new lighting design model that supports night-time leisure activities in mass housing open spaces in the contemporary urban context.

The second part of this inquiry comprised the exploratory case study [26] of lighting quality in open public space of the "Eastern City Gate of Belgrade" housing settlement in Serbia, designed and built in the second half of the 20th century. The selection of the case study area is based on extreme spatial characteristics of space from the aspect of morphology, the relationship between open public space and the built structure. The modernist environment and the post-socialist transition are testing grounds for demonstrating changes in the value system [27] and cultural changes of lifestyle. Due to the specific historical and geographical context in which it originated, post-war modernist architecture developed a 
distinct style and identity during this period; thus, it can be classified as heritage [28].

The data sourcing is carried through qualitative analysis of recreational dimension of open public space through observation of day-time and nigh-time outdoor activities and quantitative analysis of existing lighting situation. The observation of outdoor activities in open public space is executed from April to November when climate conditions are suitable for outdoor activities. The open public space has been observed in different periods of the day: in the morning, mid-day time, afternoon, evening, and night-time, and informal interviews with users were conducted. The mass housing settlement is analised from three aspects: (1) functional (program); (2) physical (structural) and symbolic (inherited) values.

Table 1 Relationship between recreational activities and lighting design type in mass housing open public spaces

\begin{tabular}{|c|c|c|c|c|}
\hline $\begin{array}{l}\text { Type of kinetic } \\
\text { experience }\end{array}$ & $\begin{array}{c}\text { Recreational } \\
\text { activities }\end{array}$ & $\begin{array}{c}\text { Limitation for outdoor } \\
\text { activities rhythm }\end{array}$ & Specific lighting design request & Lighting design type \\
\hline \multirow{4}{*}{ Passive } & walking & none & $\begin{array}{c}\text { Orientation } \\
\text { Perceiving obstacles } \\
\text { Pleasant ambiance } \\
\text { Perception of environmental characteristics }\end{array}$ & $\begin{array}{c}\text { Functional lighting } \\
\text { Ambient lighting } \\
\text { Decorative architectural lighting }\end{array}$ \\
\hline & sitting & none & $\begin{array}{c}\text { Orientation } \\
\text { Perceiving obstacles } \\
\text { Pleasant ambiance } \\
\text { Perception of environmental characteristics }\end{array}$ & $\begin{array}{c}\text { Functional lighting } \\
\text { Ambient lighting } \\
\text { Decorative architectural lighting }\end{array}$ \\
\hline & reading & none & $\begin{array}{c}\text { Adequate illuminance level } \\
\text { Pleasant ambiance } \\
\end{array}$ & $\begin{array}{l}\text { Functional lighting } \\
\text { Ambient lighting }\end{array}$ \\
\hline & board games & low & $\begin{array}{l}\text { Adequate illuminance level } \\
\text { Pleasant ambiance }\end{array}$ & $\begin{array}{l}\text { Functional lighting } \\
\text { Ambient lighting }\end{array}$ \\
\hline \multirow{4}{*}{ Medium } & running & none & $\begin{array}{c}\text { Orientation } \\
\text { Perceiving obstacles }\end{array}$ & $\begin{array}{l}\text { Functional lighting } \\
\text { Ambient lighting }\end{array}$ \\
\hline & exercising & medium & $\begin{array}{l}\text { Adequate illuminance level to perform activities } \\
\text { Pleasant ambiance }\end{array}$ & $\begin{array}{l}\text { Functional lighting } \\
\text { Ambient lighting }\end{array}$ \\
\hline & $\begin{array}{l}\text { informal } \\
\text { gatherings }\end{array}$ & high & $\begin{array}{c}\text { Perceiving obstacles } \\
\text { Pleasant ambiance } \\
\text { Space use limitation by lighting control systems }\end{array}$ & $\begin{array}{c}\text { Functional lighting } \\
\text { Ambient lighting } \\
\text { Decorative architectural lighting }\end{array}$ \\
\hline & $\begin{array}{c}\text { formal } \\
\text { gatherings }\end{array}$ & high & $\begin{array}{c}\text { Orientation } \\
\text { Perceiving obstacles } \\
\text { Pleasant ambiance } \\
\text { Perception of environmental characteristics } \\
\text { Space use limitation by lighting control systems }\end{array}$ & $\begin{array}{c}\text { Functional lighting } \\
\text { Ambient lighting } \\
\text { Decorative architectural lighting }\end{array}$ \\
\hline \multirow{3}{*}{ Dynamic } & cycling & low & $\begin{array}{l}\text { Orientation } \\
\text { Perceiving obstacles } \\
\text { Pleasant ambiance }\end{array}$ & $\begin{array}{l}\text { Functional lighting } \\
\text { Ambient lighting }\end{array}$ \\
\hline & skateboarding & medium & $\begin{array}{c}\text { Orientation } \\
\text { Perceiving obstacles } \\
\text { Pleasant ambiance } \\
\text { Space use limitation by lighting control systems }\end{array}$ & $\begin{array}{l}\text { Functional lighting } \\
\text { Ambient lighting }\end{array}$ \\
\hline & sports & high & $\begin{array}{l}\text { Adequate illuminance level to perform activities } \\
\text { Pleasant ambiance } \\
\text { Space use limitation by lighting control systems }\end{array}$ & $\begin{array}{l}\text { Functional lighting } \\
\text { Ambient lighting }\end{array}$ \\
\hline
\end{tabular}

The analysis of the existing lighting situation is conducted following systematised lighting quality parameters for open public spaces and pedestrian zones: (a) selection of the light source, luminaire type, optical features, and the physical arrangement; (b) illuminance level and overall uniformity; (c) light pollution; (d) the users ' feeling of safe and secure space and (e) the specific elements and points of interest. The quantitative analysis of the existing lighting situation is recorded by measuring the illuminance level in a characteristic segment of the open public space. The ground level was taken as the reference surface on which the levels of horizontal illuminance of the space were recorded. It is of great importance that the reference surface is not covered with equipment or other elements of the space. When the area under examination had an irregular shape or dominant pedestrian activities, the evaluation points were set as nodes of a square network [29]. The measured values of the level of horizontal illuminance were recorded at the evaluation points at $1 \mathrm{~m}$ intervals on the dominant pedestrian routes and $2 \mathrm{~m}$ intervals in other areas. Measurements of the representative sample were conducted using the lux-meter/chroma meter Konica
Minolta CL-200A which provided the function of illuminance measurement in a very wide range of 0.1 99990 lx.

At the end of the inquiry, in a descriptive mode, the proposed model is illustrated and evaluated through the lighting quality of the improvement scenario following the proposed lighting design model through three types of lighting - functional, ambient, and architectural decorative. A step towards the operationalisation of the lighting design model and its implication to the architectural practice, by recognising the importance of the night hours as a time frame for recreational activities and striving to explain contemporary ways of use, highlight the safety and preservation of symbolic values of open public space.

By analytic generalisations, the goal of the case study is to expand theories in lighting design and enlighten the relation of lighting and the recreational dimension of open public space. The limitation of this research is conditioned by the application to open public spaces of similar morphologies: isolated position of residential settlement in relation to urban context; a position of open public space in the settlement; typology defined by skyscrapers and open public area for outdoor activities. 


\section{RESULTS}

\subsection{Case Study Area: The Residential Settlement of the "Eastern City Gate of Belgrade"}

The spatial unit of open residential settlements known as the "Eastern City Gate of Belgrade" represents a city district that is an example of residential developments formed under the socialist ideology in the territory of Belgrade, Serbia. The shift in contemporary cultural patterns has resulted in the neglect of the spatial and cultural values of this architectural style and in a dissonance between the level of space adaptation and contemporary users' needs. In the contemporary context, these spaces can be spontaneously transformed into leisure spaces, enabling the development of various activities and new modes of use within the existing built structure.

The open-formed residential settlement is situated on the former outskirts of the city, characterised by the mid20th century industrial development and the need for residential expansion to accommodate industrial workers. The built structure represents a landmark at the east side of city access, considering the vicinity of the highway and the regional arterial road. The dominance of the three skyscrapers at the entrance of the city is responsible for the name of the "Eastern City Gate of Belgrade" (Fig. 1).

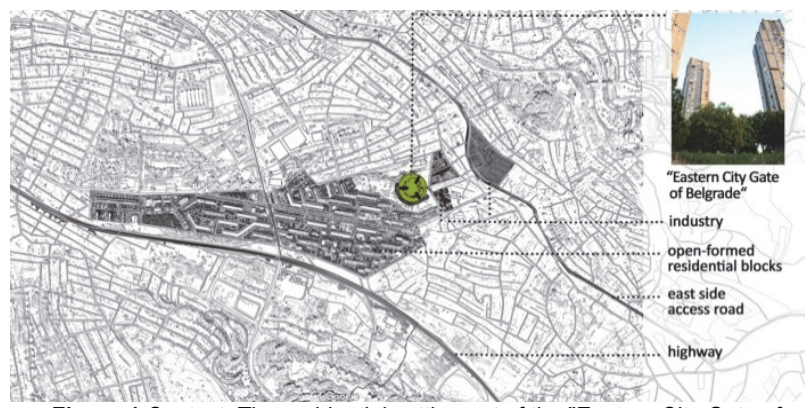

Figure 1 Context: The residential settlement of the "Eastern City Gate of Belgrade"

The residential settlement of the "Eastern City Gate of Belgrade" represents the new concept of modernist residential architecture, historically speaking - a big step for the future development of Belgrade and the quality of life; mass housing settlement that personates a new concept of everyday life founded on rituals and routines through multisensory impressions imparted by a new ambience for the neighbourhoods built during the modernist period. These spaces were designed with a clearly defined mode of use in mind, adhering to a strict distinction between work and free time [28]. Therefore, the spaces were specifically designated for planned activities. Rhythm of life was organised in clear time sequences, assumed five working days in a week, and the remaining two days were the weekend, dedicated to free time; i.e. resting, relaxing from work and maintaining health by pursuing sport activities. On a daily basis, this mode comprised 8 hours of work, taking place outside the home; this was followed by 8 hours of free time dedicated primarily to spending time in open public spaces, cultural venues or perhaps in personal or communal spaces of a housing unit; the remaining 8 hours were meant for sleeping i.e., night-time rest spent at home. This routine was stimulated with spaces such as parks, playgrounds, sports centres and hotel accommodation.

This part includes mapping of the activities of the observed space, in order to recognise the needs of the users and their relation towards the space in the contemporary moment. The mapping of key features defining the framework for the development of the recreational dimension of community spaces through the following aspects: (1) physical context, (2) program (functional) context, and (3) symbolic (inherited) values are presented in the diagram (Fig. 2).

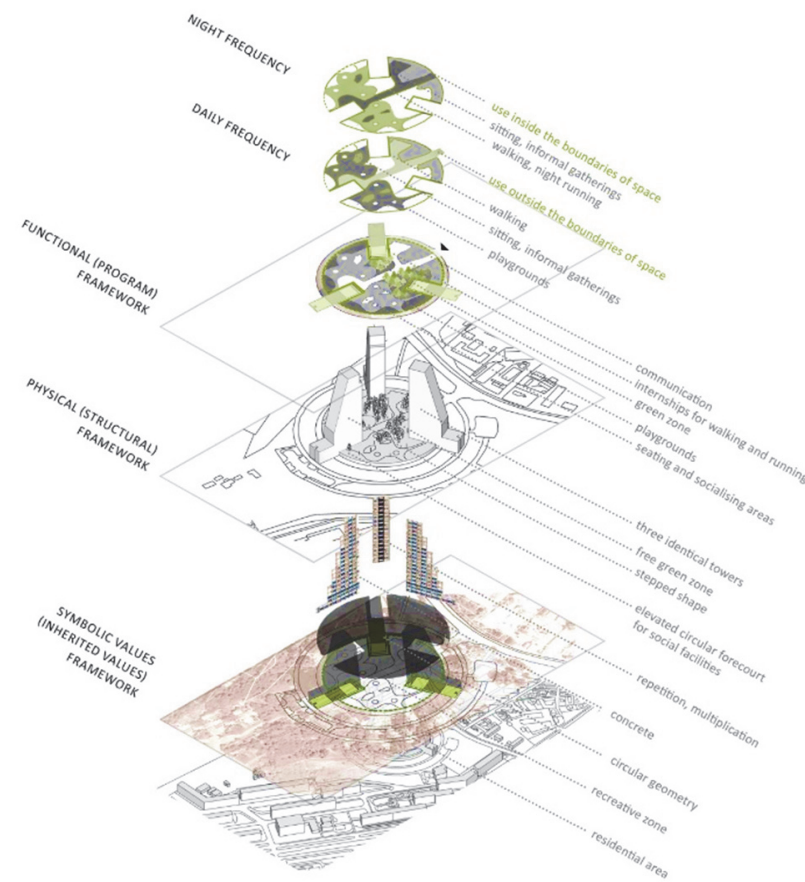

Figure 2 Community space of the residential settlement: outdoor activities

\subsection{Characteristics of the Existing Lighting Situation in the Open Public Space}

This paper analyses light quality parameters through horizontal illuminance, the referent for open public spaces based on the field measurements. Furthermore, the values manifested through light influence the users' experience; the quality of lighting is based on perception (Fig. 3). The qualitative and quantitative analysis of the existing lighting is based on the estimation of the reference public lighting parameters: (a) selection of the light source, luminaire type, optical features, and the physical arrangement (number, position, height, etc.); (b) illuminance level and overall uniformity; (c) light pollution; (d) the users' feeling of safe and secure space; and (e) the specific elements and points of interest.

(a)

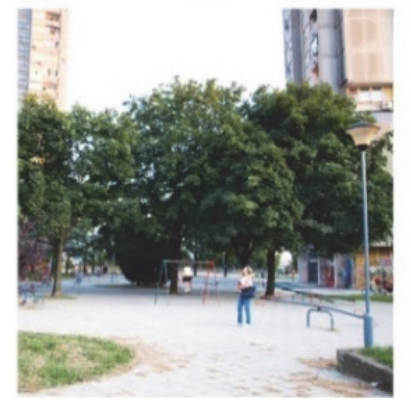

Figure 3 Community space of the residential settlement: (a) during the day; (b) during the night (b)

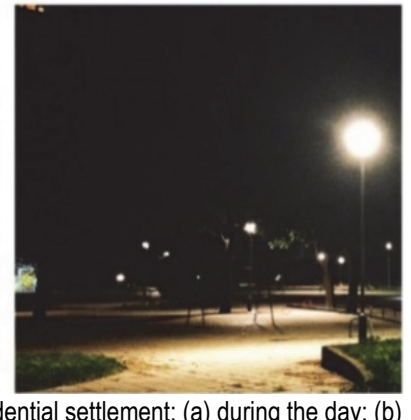

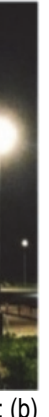
) 
(a) Selection of the light source, luminaire type, optical features, and the physical arrangement

The arrangement of luminaires at the location (on the car-free circular forecourt) emphasises the users' pedestrian paths and the geometry of the designated zones intended for outdoor activities. An uninterrupted flow of activities has contributed to the arrangement of luminaries and discrepancies in distance ranging from 19 to $25 \mathrm{~m}$ (Fig. 4 and Fig. 7).

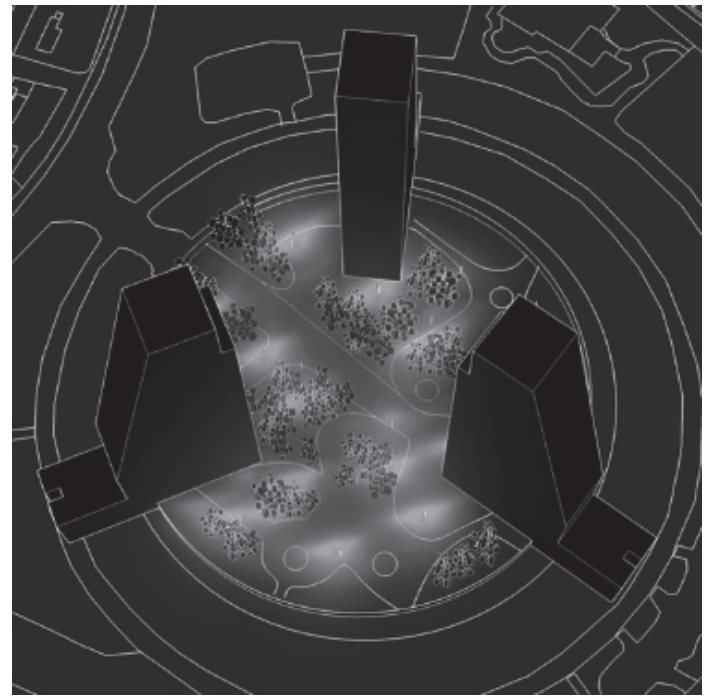

Figure 4 Community space: Existing lighting design, the arrangement of luminaires

The lighting of the central lane is enabled by the onesided arrangement of the luminaires at varying intervals.
The boundaries of the forecourt are emphasised by the elevation of the ground and the public road lighting (below the circular forecourt) which follows the foundation geometry defined by the one-sided arrangement of the luminaires.Existing lighting design solution is based on the selection of one type of luminaire. The installed fixture represents another specific heritage feature, influenced by the socialism of former Yugoslavia, as one of the typical applications within open public spaces of that period (Fig. 5). (a)

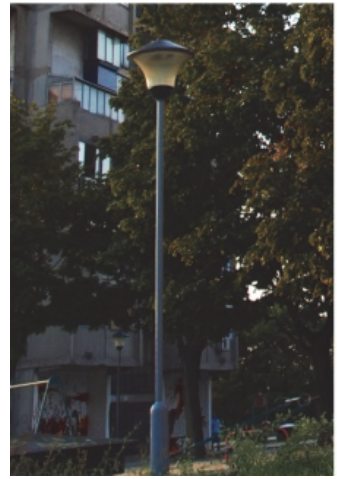

(b)
Figure 5 Installed luminaire

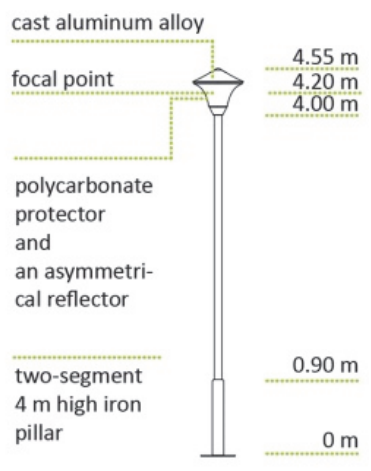

$0 \mathrm{~m}$
The light source is metal-halide, with a nominal power of $100 \mathrm{~W}$, and a warm white average temperature of approximately $2700 \mathrm{~K}$ (Fig. 6). The illumination of the forecourt is achieved by the installed luminaires. There are no additional effects of coloured lighting, while the warmwhite light source creates an agreeable ambiance.

\section{POLAR LIGHT DISTRIBUTION}

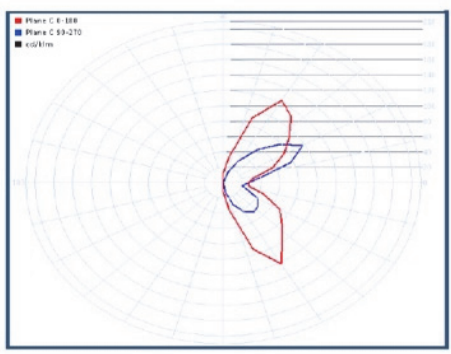

\section{CARTESIAN LIGHT DISTRIBUUTION}

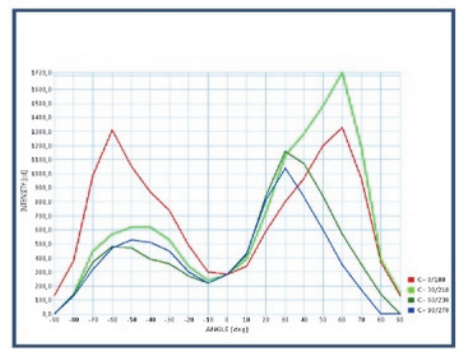

\section{ISOLUX DISTRIBUTION}

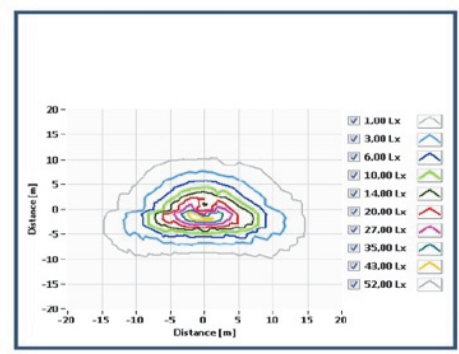

3D LIGHT DISTRIIBUTION

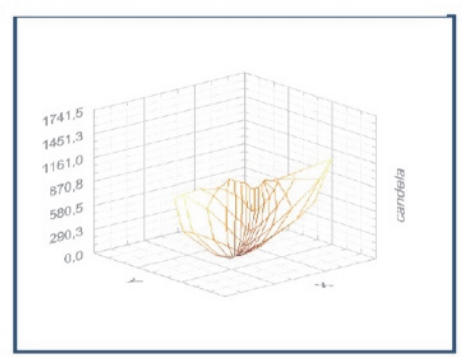

Test Description:

Measure distance: $10,0 \mathrm{~m}$ Lateral pitch: $10^{\circ}$

Lateral scan angle: $360,0^{\circ}$

Light sensor: Minolta CL-200A

Lamp height: $4 \mathrm{~m}$

\section{CHROMATIC ABERATION}

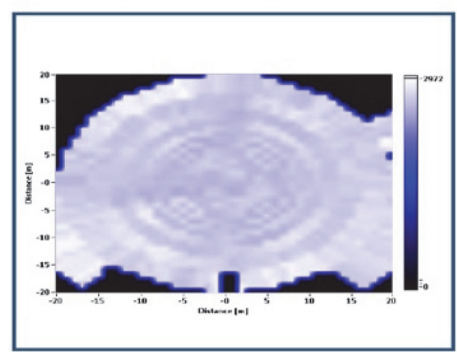
Average color temperature: $2631 \mathrm{~K}$
Gama 0 color temperature : $2691 \mathrm{~K}$
Min color temperature $\begin{array}{ll}\text { Min color temperature : } & 2473 \mathrm{~K} \\ \text { Max color temperature : } & 3241 \mathrm{~K}\end{array}$

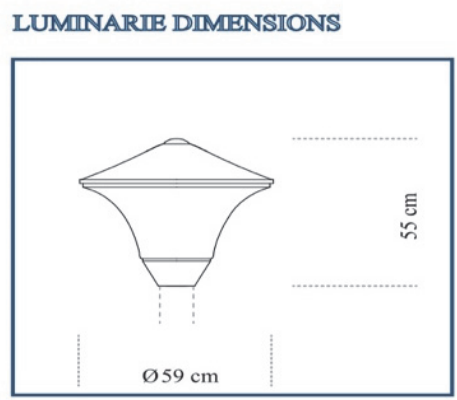

Lamp Description:

Luminarie category: MH Laminarie: SVETILJKA Rated lumens: (Lamp) $9095 \mathrm{~lm}$ / (Luminaire): $3118 \mathrm{Im}$ Power: $100 \mathrm{~W}$ Average color temperature: $2631 \mathrm{~K}$ Min color temperature: $2473 \mathrm{~K}$ Max color temperature : $\quad 3241 \mathrm{~K}$

Figure 6 The light source: Test measurement report 


\section{(b) Illuminance level and overall uniformity}

The tested space can be classified as a low-activity space (residential zone)[21]. The public open space is located within the urban context [22] and the influence of the surroundings i.e., the influence of the lighting from the neighbouring areas is low [23].

According to the chosen guidelines for pedestrian areas design, the public space of the open-formed residential blocks is classified as a residential zone by the Illuminating Engineering Society (IESNA) [21]. The public space area under consideration is characterised by a very low speed of motion, low pedestrian traffic density, absence of parked vehicles and low surrounding luminosity; thus, it is qualified as the lighting technical class P6 under the International Commission on Illumination (CIE) standard [22]. As proclaimed by the recommendation of the British Standards Institution (BS EN) standard [23], this zone falls into the lighting technical class E1, and into class S5 according to the parameters related to pedestrian frequency, risk of criminal activity and the luminosity of distinctive surroundings for an urban area. According to the above standards, the recommended values of the horizontal illuminance are presented in Tab. 2. The average uniformity for a residential area is not defined; however, the proposed maximum to minimum overall uniformity is $10: 1$ and the average to minimum value is $4: 1$ [30].

The measurement of the illuminance level within the former community space has been carried out on a characteristic space segment with overlapping zones representing inadequately illuminated places in relation to the architectural heritage values of the space and the spontaneously created activities in accordance with the contemporary lifestyle. Zone 1 represents the areas where leisure activities were observed, and Zone 2 represents the contact zone of the buildings (dominant facilities that create the identity of the settlement) and the forecourt (open public space planned for the development of outdoor activities) (Fig. 7).

Zone 1 is defined by the areas intended for the development of outdoor activities. This zone encompasses the access points to the residential building's entrances, as well as the forecourt and green areas which are covered not only by low greenery but also a number of high trees. The measured values of the minimal horizontal illuminance of this zone are in accordance with the recommended values (Tab. 2).

Zone 2 represents an interface between the open public space and the surrounding buildings. The illuminance level in this zone also conforms to the recommended values for the minimum and average horizontal illuminance (Tab. 2).

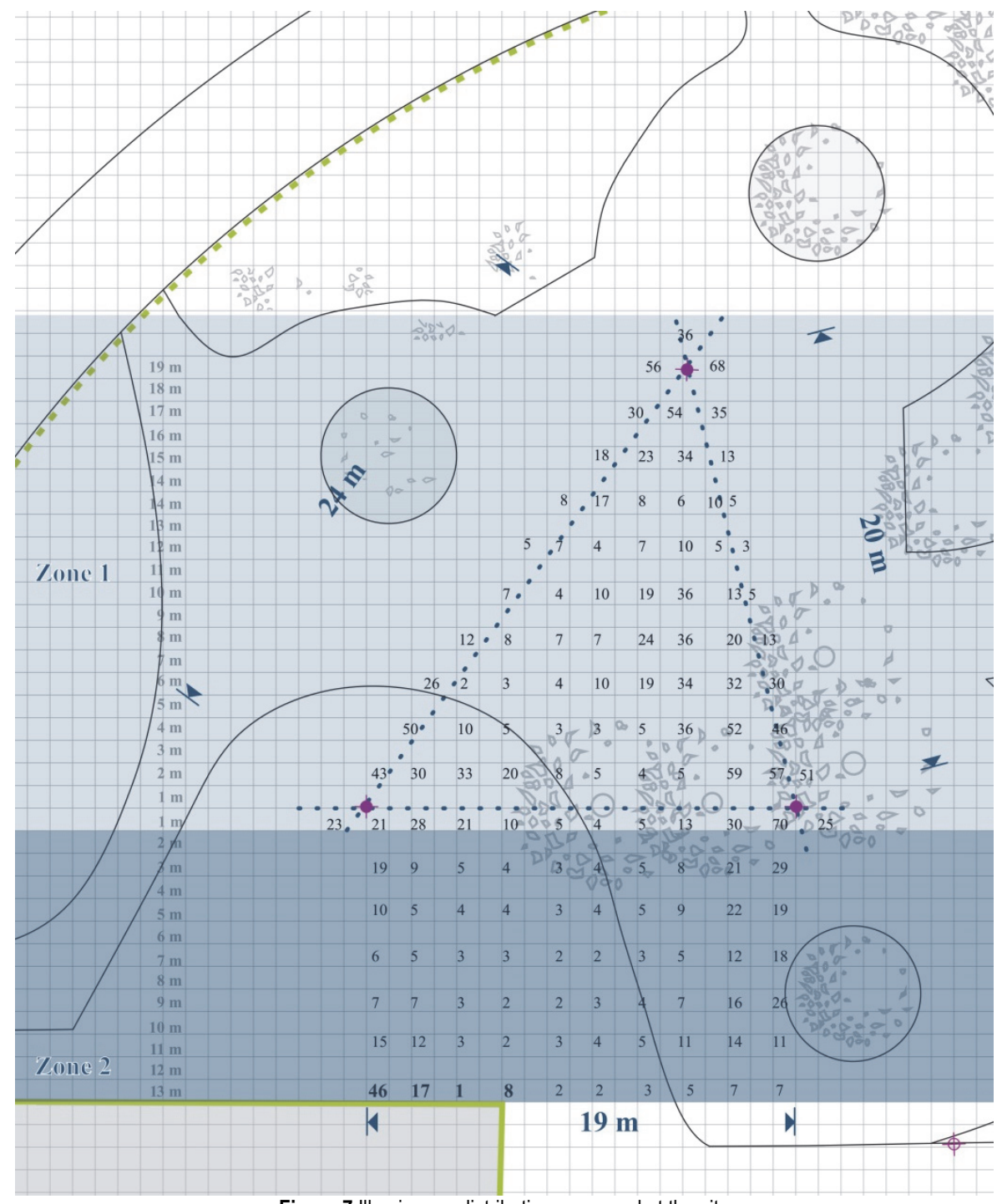

Figure 7 Illuminance distribution measured at the site 


\begin{tabular}{|c|c|c|c|c|}
\hline Result type & $\begin{array}{c}\text { Min. horizontal } \\
\text { illuminance }\end{array}$ & $\begin{array}{c}\text { Average horizontal } \\
\text { illuminance }\end{array}$ & $\begin{array}{c}\text { Max. horizontal } \\
\text { illuminance }\end{array}$ & $\begin{array}{c}\text { Uniformity } \\
\text { Minimum / average }\end{array}$ \\
\hline IESNA [21] & Not defined & $21 \mathrm{x}$ & Not defined & Not defined \\
\hline CIE 115-2010 [22] & $0.4 \mathrm{~lx}$ & $21 \mathrm{x}$ & Not defined & Not defined \\
\hline BS EN 13201-2:2015 [23] & $0.61 \mathrm{x}$ & $31 \mathrm{x}$ & Not defined & Not defined \\
\hline Measured values: Zone 1 & $21 \mathrm{x}$ & $15 \mathrm{~lx}$ & $701 x$ & $1: 8$ \\
\hline Measured values: Zone 2 & $11 \mathrm{x}$ & $181 \mathrm{x}$ & $461 x$ & $1: 18$ \\
\hline
\end{tabular}

\section{(c) Light pollution}

The phenomenon of light pollution comes as a consequence of excessively high contrast or poor radiance distribution in space. Direct glare is an effect of light moving directly from the source to the eye, while reflected glare can be a consequence of light reflecting from the surfaces of elements in the space. Although it can be measured [31], the open public space (the circular forecourt) in question is a car-free zone. Thus, imaging luminance measurement to determine glare has not been conducted. This event is presented as subjective impression; therefore, these values can be submitted only to qualitative presentation. Direct glare is controlled because the installed luminaire is half-shaded and the protector acts as a diffusor at the same time. Users' impressions of surface brightness and light reflections are obscured by the finishing of the pedestrian walkways, made of concrete pavement with a low reflection degree $(0.20)$.

\section{(d) Users' feeling of safe and secure space}

The principal significance of this lighting parameter is to create an experience of a secure space. Security can be defined as the absence of danger, while safety is the absence of the users' concern for safety in space and is therefore considered as the psychological version of security [21]. Albeit the level of illuminance complies with the standards (Tab. 2), the overall uniformity, which enables the eye to adapt to the changes in luminance and allows the easy recognition of faces and elements in space, is questionable and does not leave an impression of a safe and secure ambiance.

\section{(e) The specific elements and points of interest}

The existing lighting does not support the appearance of the built structure as these are residential buildings, and the lighting was designed as functional, so there is no additional lighting used to emphasise the architectural values.

The level of the horizontal illuminance is in accordance with the recommended values proclaimed by the reference standards for the design of open public space lighting. The differences in the level of horizontal illuminance at certain measuring points are considerable because the greenery in this zone creates a number of shadows, but this did not affect the uniformity of illumination to a great extent. Major discrepancies of the lighting level originate from the deficiency of the illumination border zones between the buildings and the forecourt. This appearance has created unevenness and significant deviation from the 1:10 ratio set by the recommendations for the residential zones [30].

Due to the major level of discrepancy, the overall illuminance uniformity within the settlement does not leave an impression of a safe and secure ambiance, which contributes to the absence of outdoor activities during evening hours.

\subsection{Guidelines for Improving the Recreational Potential in Open Public Spaces During Night-Time Hours - The Evaluation of Proposed Lighting Design Model}

Examining the characteristics within the housing development has shown that the decrease in the level of activities at night time is a consequence of the lighting quality. The revitalisation of the former community spaces in mass housing settlements can be achieved by improving the lighting quality and affirming the symbolic values, but also by adopting newly-formed patterns of use of the open public spaces by supporting the concepts of their transformation into leisure spaces. With the aim of improving their recreational quality in a night time mode of use, this research proposes model for improvement through the affirmation of the key architectural aspects: (1) physical context, (2) program (functional) context and (3) symbolic values (Fig. 8).

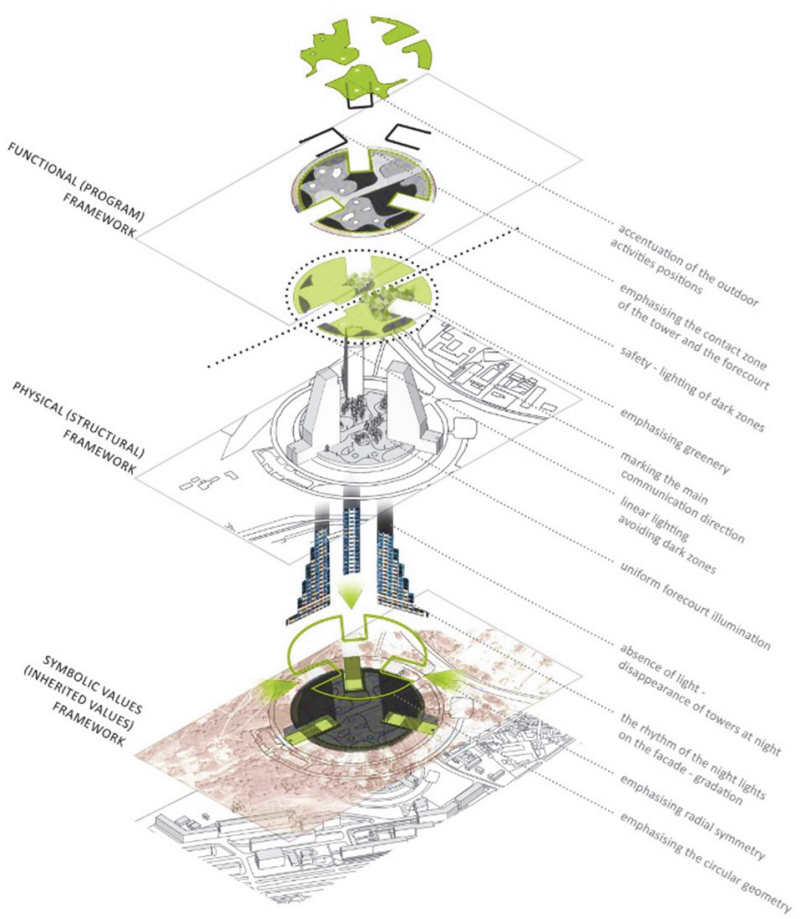

Figure 8 Community space of the mass housing settlement: guidelines for improving the recreational potential within spaces during night-time hours

\subsubsection{Lighting as a Medium of Improvement: Physical Context}

With the aim of preserving the spatial characteristics and inherited forms of the housing complex of the "Eastern City Gate of Belgrade", it is important to emphasise the routes of movement which prioritise symmetry, as well as the rhythm and repetition reflected in the multiplication of the structures' volumetric qualities. Although the research has shown that the level of illuminance of the movement 
route is following recommendations and regulations, it is possible to additionally support the inherited physical framework and mark the primary direction of communication by using walkways and ground lighting; i.e., providing pathway lighting [21]. The accentuation of the circular geometry of the forecourt the foundation on which the housing development is formed is of the utmost importance for determining the physical context of this unit, and at the moment, it is unmarked by light and includes the presence of dark areas. It is possible to uphold this specificity of space by means of linear lighting that would highlight the boundaries but also the continuity implied by the circular shape of the forecourt. The transparency of the articulation of the ground level via defined green areas, as well as free multi-use spaces, presents positions which allow the development of leisure activities. It is necessary to further illuminate these areas, which are positioned symmetrically to the forecourt's access route, in order to reinforce the inherited, defined structure of the space emphasised by denivelation in the form of planters. The contact areas of the structures and the forecourt, which the research recognised as leaving the impression of being unlit and very dark, should be illuminated and thus emphasise the boundary between the public space and the structures that require a greater degree of privacy (Fig. 9).

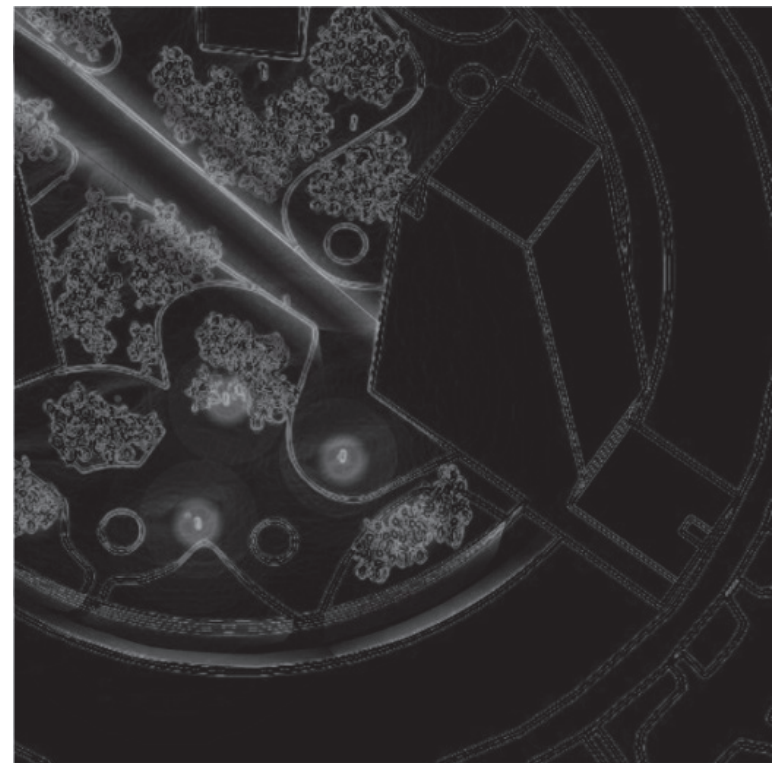

Figure 9 Lighting design proposal for community space of the mass housing settlement: lighting as a medium of improvement physical context

\subsubsection{Lighting as a Medium of Improvement: Program (Functional) Context}

For uninterrupted outdoor activities, it is vital to establish a space where users feel safe. Examining the lighting quality within the community spaces has shown that the present illuminance of the movement routes complies with the regulations and guidelines for designing lighting for housing estates; however, the space fails to encourage night-time activities due to the frequent occurrence of dark areas which feel unsafe to users. Additional accentuation of the positions through a greater level of illuminance could promote the development of the above-mentioned leisure activities and remove the occurrence of undefined spatial boundaries caused by decreased visibility.

Although the level of illumination achieved within the space is in compliance with the standards and regulations for designing lighting (minimal up to $1 \mathrm{~lx}$, average up to $3 \mathrm{~lx}$ ), the problem is the overall uniformity due to the inadequate illumination of some areas and the presence of unsafe dark corners. Leisure activities such as relaxation, conversation and socialisation can be performed under $3 \mathrm{~lx}$ with warm white light. For specific leisure activities, it is crucial to provide lighting that will anticipate the needs of different outdoor activities: reading, open space recreation, spontaneous activities such as street art, skateboarding, rollerblading, etc. These activities require a higher level of illuminance for specific tasks: riding requires $15 \mathrm{~lx}$, while more demanding tasks such as reading and board games can require up to $20 \mathrm{~lx}$ of neutral white light. Accordingly, some of the spaces in which it is possible to promote the development of these activities need additional lighting in line with their specific requirements.

It is necessary to eliminate the occurrence of dark areas by introducing additional lighting that would emphasise the contact area between the buildings and the forecourt, since activities such as the riding of bicycles and scooters were noticed there. On the rim of the circular forecourt, the emergence of night running was observed, which calls for the forecourt's surface to be accentuated so that obstacles become visible. The forecourt's positions that are already illuminated support gatherings; however, the positions of uneven planters are not adequately illuminated due to the presence of tall vegetation and shadows, so they leave the impression of an unsafe space. These positions, given that they provide a pleasant space for reading, working outdoors, socialising and the creation of street art, require additional lighting (Fig. 10).

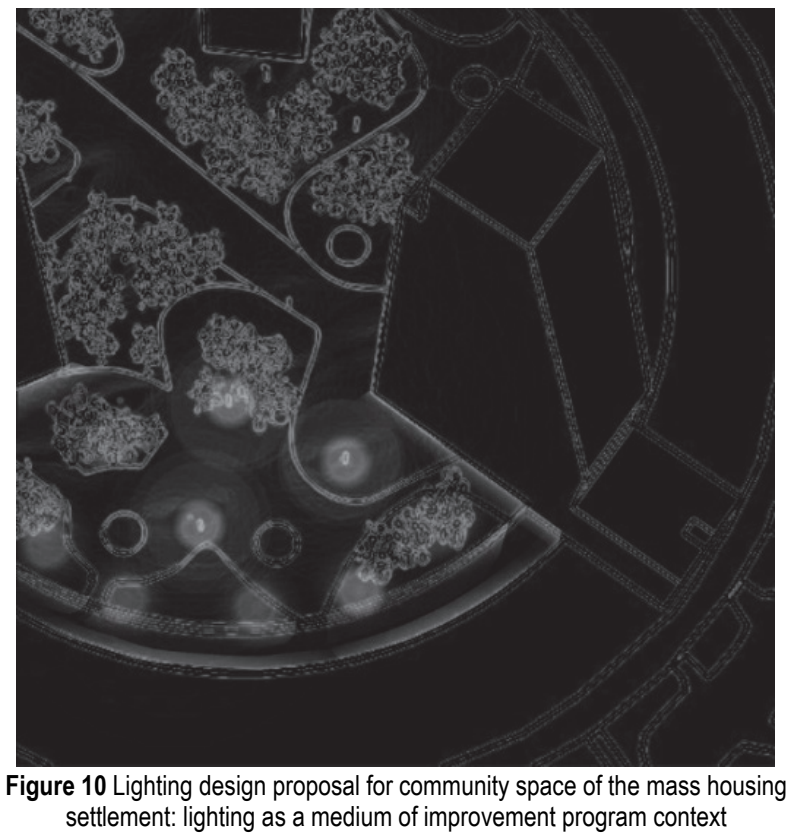

When emphasising specific areas, it is necessary to determine the positions and types of luminaires so that they can be directed towards the ground level, avoiding glare and disturbance to the apartment buildings. In addition, when promoting certain activities, the light colour effects 
should be adjusted and the occurrence of the stroboscopic effect should be eliminated. Light colour effects can be significant for the development of certain activities on the ground-level surface and in the green areas as well. The colour temperature of the light source should be adjusted to the activities and their specific requirements. It is also possible to use a light source with a higher colour temperature so that the cold white light effect would create the impression of a higher level of illuminance using the same horizontal illuminance level. On the other hand, areas intended as relaxation spaces should have light sources with a lower light colour temperature in order to achieve the impression of a more intimate ambiance.

When conducting diverse outdoors activities, it is very important to achieve quality light distribution within the space; therefore, it is essential to pay attention to overall uniformity, which should not exceed a 1:4 ratio.

\subsubsection{Lighting as a Medium for Improvement: Symbolic Dimension}

To preserve the characteristics of space and inherited forms of the housing settlement of the "Eastern City Gate of Belgrade", it is important to emphasise the circular geometry of the foundation upon which the three high-rises were erected. This neighbourhood represents a dominant structure in space, as a landmark visible from different directions. The circular geometry of the platform is supported by the illuminated traffic road outlining the housing complex; however, the transparency of this forecourt and its position as a community space (within housing complex) is annulled. The non-illuminated forecourt rim has completely dematerialised this boundary, so the introduction of additional lighting to accentuate its circular geometry is required. The pedestrian access route emphasises the symmetry of the forecourt, which is backed by the position of the high-rises, but also by the symmetry in the spatial layout of the ground level. The access route is marked by functional lighting, but it is possible to complement this by adding ground lights that accentuate the forecourt's axis of symmetry. The specificities of the architectural expression values are illustrated through rhythm and repetition, perceived through both the multiplication of the buildings' volumetric qualities and the sequence of facade openings. The monolithic impression has been achieved through the uniformity of the material (concrete). The monolithic effect can be preserved during the night hours by the even illumination of surfaces. The emphasis of the skyscrapers' dominant volumetric quality, given their content of residential units, is achieveable on the ground level which would define the contact areas of different levels of privacy. It is necessary to take care that the additional lighting does not disturb the activities within the structures, which was already noted in the section on emphasising the physical framework of the space. The specificities of the forecourt's space are marked by the dominant structures, which direct the attention towards the sky when observing the totality of the built structure, so the impression of the high-rises fading into heavens should not be disturbed by the additional lighting of their roofs. The appearance of the buildings at night time seen from a greater distance is enabled by the light penetrating through the facade openings, thus contributing to the dynamics and the ephemerality of the structure, regardless of the rigidity of the architectural expression (Fig. 11).

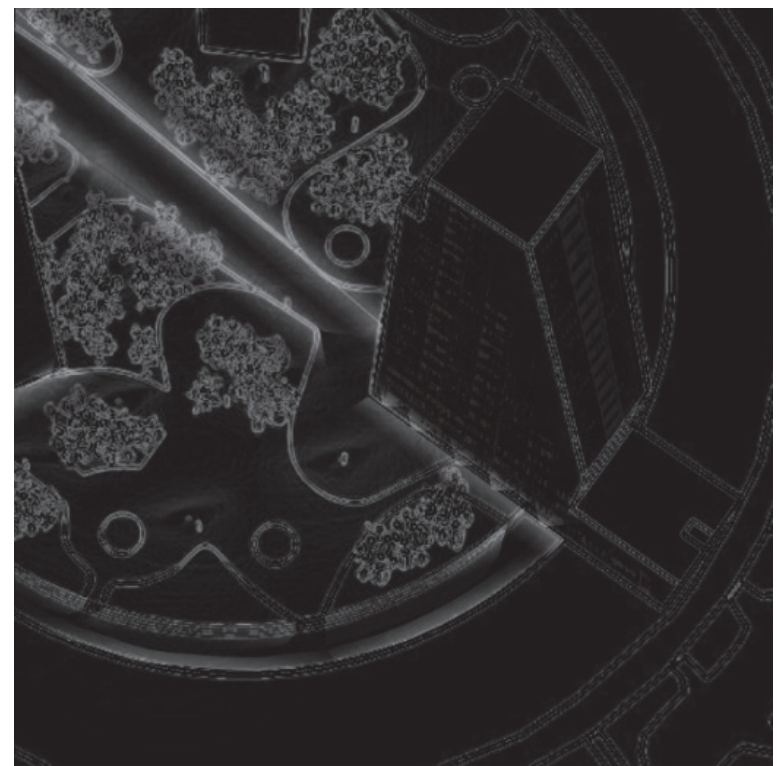

Figure 11 Lighting design proposal for community space of the mass housing settlement: lighting as a medium of improvement symbolic values

\subsubsection{Lighting as a Medium for Improvement: The Leisure Activities Within Open Public Space of the Mass Housing Complex of the "Eastern City Gate of Belgrade"}

The analysis shows that increasing the recreational quality of the former community spaces can be achieved by improving the lighting quality with defined criteria: (1) physical context, (2) program (functional) context and (3) symbolic values. Overlapping the response in terms of each criterion, the proposal to enhance the quality of lighting within the open public space of the housing complex of the "Eastern City Gate of Belgrade" is formed (Fig. 12).

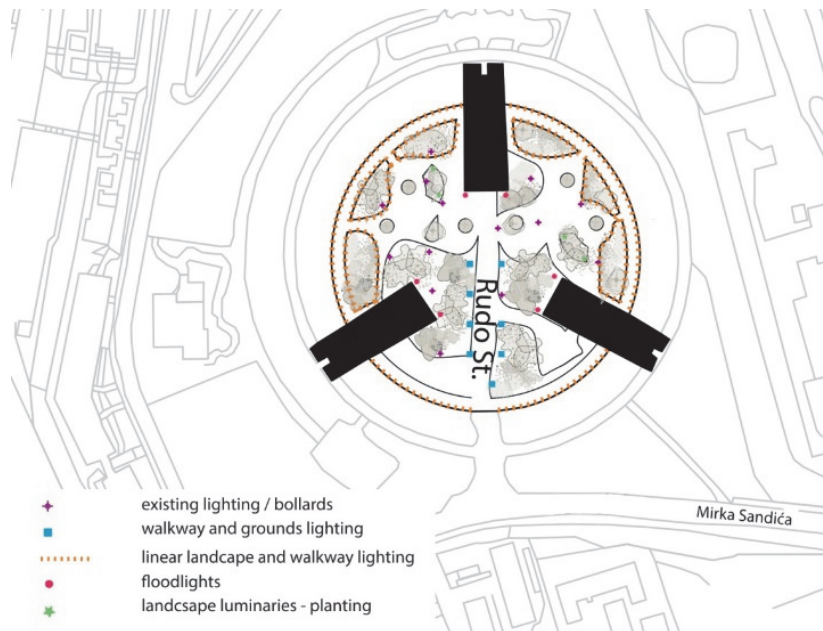

Figure 12 Community space of the mass housing settlement: proposal for improving the lighting quality

The existing lighting installation is kept, and so are the luminaries, which represent the inherited value of the space. However, some additional types of luminaries are added to promote spontaneous activities (Fig. 13). 
(a)

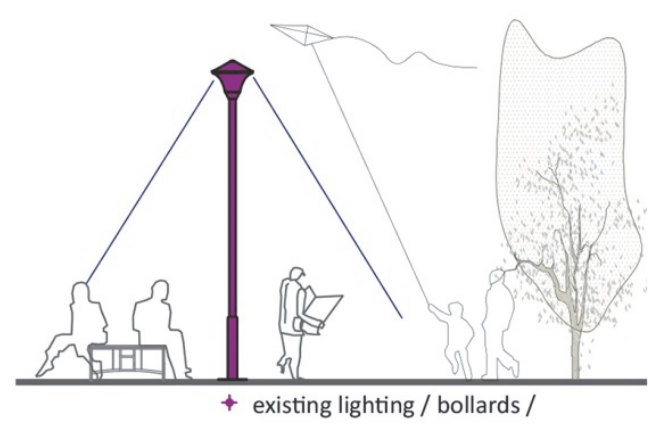

(c)

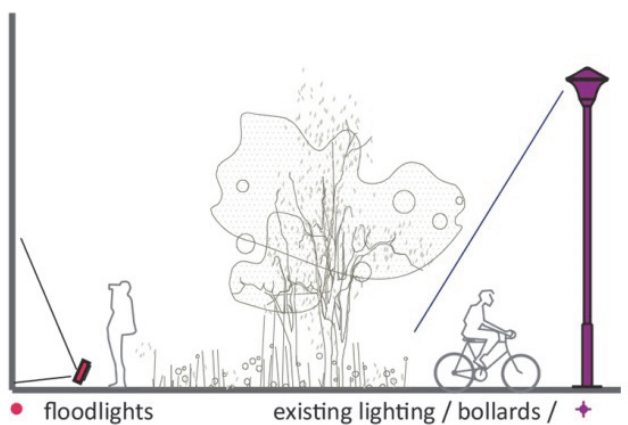

(b)

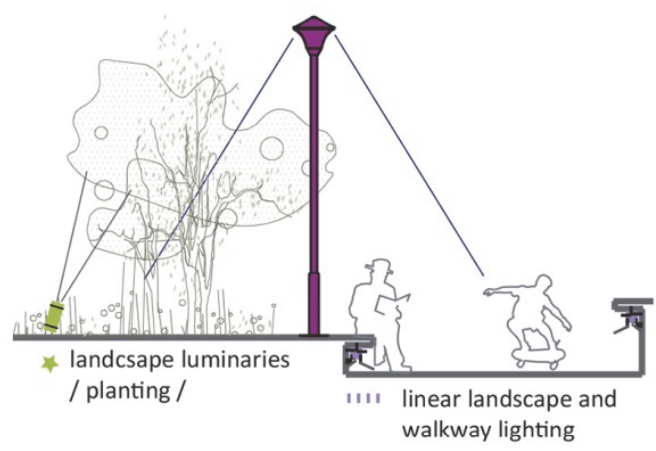

(d)

Figure 13 Proposal for improving the lighting quality. Luminaire type: (a) existing lighting/bollards; (b) landscape luminaries-planting and linear landscape and walkway lighting; (c) floodlights; (d) walkway and ground lighting

\section{DISCUSION AND CONCLUSION}

Open public spaces in mass housing modernist settlements, designed as community spaces, spontaneously tend to transform into leisure spaces under contemporary circumstances. When considering the improvement of the recreational quality of former community spaces, research has shown that the development of outdoor activities in line with today's lifestyle is to a great degree inhibited by the quality of the lighting present within these spaces.

Due to the change in the neighbourhood relations of the post-socialist development of the city [8], which is noticeable through the expansion of types and regimes of activities, there is a need to adapt the former community spaces to the new values of the collective. By improving the quality of lighting, it is possible to increase the development of leisure activities in accordance with the urban lifestyle, achieving multiple kinds of sustainability. According to social sustainability, through the common activities of social interactions, lighting enables safe activities, as well as the mapping of appropriate content in the night mode of use without physical transformations. According to cultural sustainability, through the encounter with cultural heritage and the learning of the environment [15], it is possible to achieve the adequate visibility of the elements of the space, as well as to interpret the appropriate experience of inherited values through lighting. In accordance with ecological sustainability, through controlled energy consumption and the preservation of existing resources [32], the application of adequate types of lighting enables energy savings but also the absence of invasive methods of space transformation.

In terms of energy-efficiency and maintenance, the use of a contemporary LED light source would be advisable.
However, the application of contemporaneously designed LED-based luminaries could affect aspects of the architectural heritage. An LED retrofit into existing light fixtures would keep that aspect intact; however, certain technical issues may arise, such as heat transfer, optical properties and the structural adaptability of the luminaire, etc. It is important to define decision-making support tools for sustainable landscape management and planning that are applicable to the lighting design of open public spaces, besides the improvement of appearance and sense of security, considering energy and cost savings. The effects of energy efficiency and savings, as well as carbon dioxide emission and maintenance cost were not considered in detail, since the ecological, technical and economic aspects of LED technology in lighting have already been extensively researched $[33,34]$. The public lighting infrastructure integration with a smart grid can provide economic benefits, energy efficiency, and visual comfort requirements [35].

In lighting design field, open public spaces intended for pedestrians have specific requirements focused on the feeling of safety and security with the possibility of performing undemanding nocturnal activities. This objective can be achieved through a sufficient level of horizontal illuminance and the ability of face and object recognition. This quality of lighting is known as the functional aspect. On the other hand, ambient and architecture aspects of lighting comprise parameters that are measurable through experience values of space, such as the perception of the influence of light on spatial elements, their surfaces and other relations (distances, depths, etc.) and the establishment of the desired atmosphere.

The presented study gives insight into specific requirements of open public spaces in mass housing 
modernist settlements in the lighting design process. Based on theoretical grounds, the main hypothesis of the paper relied on the new definition of three types of lighting as a response to specific requirements of open public space following the contemporary lifestyle in an urban context:

(1) Functional lighting is the appropriate type according to the program framework, with the aim of the encouragement of activities;

(2) Ambient lighting is the appropriate type according to the physical framework, to improve the ambient spatial values;

(3) Decorative architectural lighting is the appropriate type according to the symbolic values framework, with the aim of affirmation of architectural heritage values and the architectural style of a space.

The research answered questions in the field of the lighting design process for contemporary use of former community spaces of modernist settlements. Specific requirements of open public spaces in terms of inherited physical structure, symbolic values, and contemporary modes of use were considered. The result of the study showed features of lighting quality that support leisure outdoor activities in an urban context. The new lighting design model for supporting leisure activities in open public spaces of modernist mass housing settlements is proposed.
Applying the model, through the exploratory case study, the potentials for the development of outdoor recreational activities in the night-time period are presented. The case study showed that the decrease of night-time outdoor activities in open public spaces is a consequence of inadequate lighting quality. The quality of lighting is analysed and tested through the proposed lighting design model for supporting night-time leisure activities in mass housing open spaces.

Correlation of leisure activities and lighting design requests, as a result of the model operationalisation through the case study of a residential complex known as the "Eastern City Gate of Belgrade", as a relevant example of a modernist mass housing settlement, is presented in the diagram below (Fig. 14). Defining the lighting quality parameters concerning recreational dimension, the recommendations for improving the leisure activities of open public space during night-time period are established. The defined lighting types are presented with specific lighting quality parameters. In the lighting design process, for supporting leisure activities in mass housing settlements, all the parameters are included, with a focus on specific ones for a different form of outdoor activities according to users' kinetic experience of space.
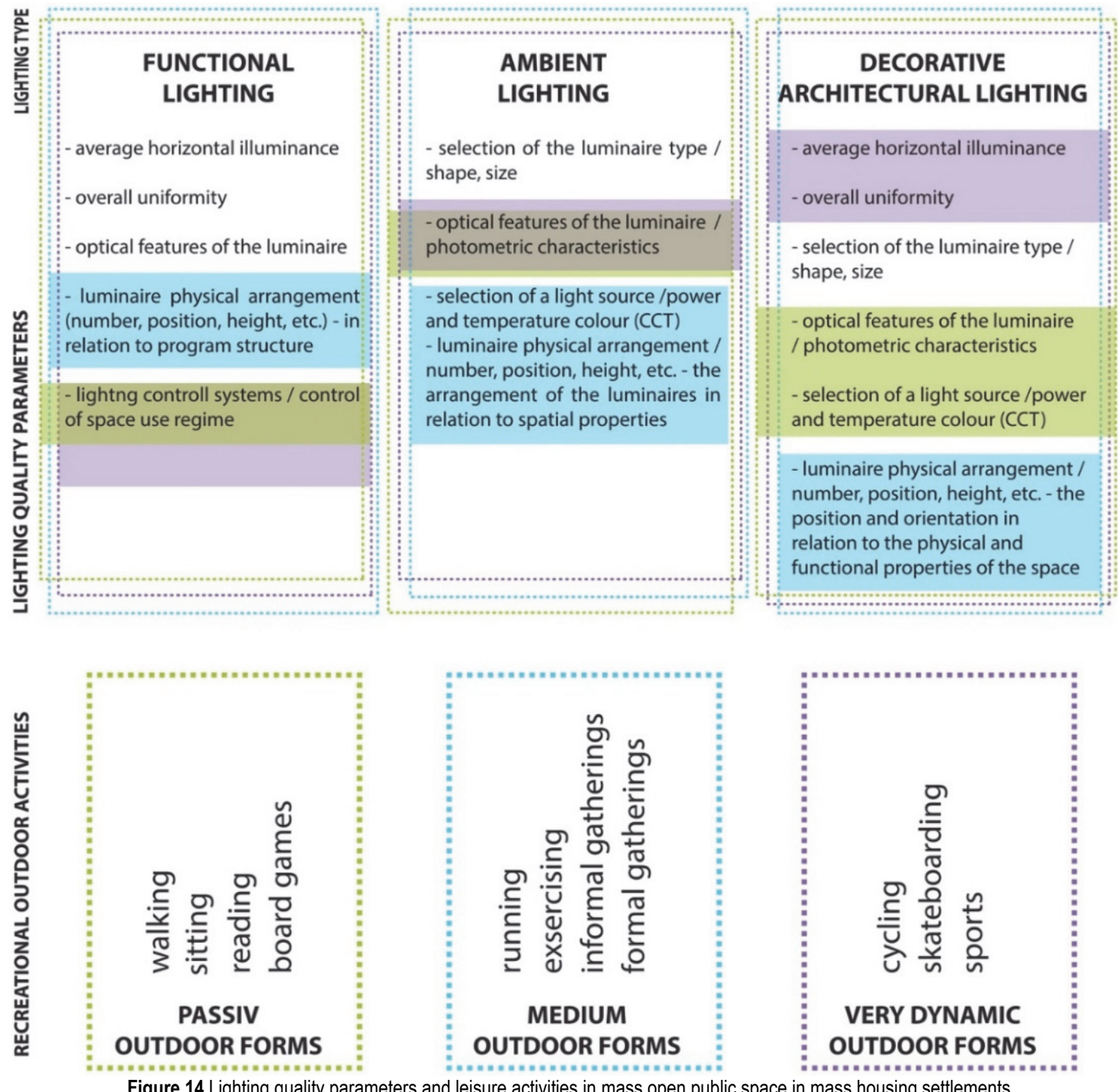

Figure 14 Lighting quality parameters and leisure activities in mass open public space in mass housing settlements 
This paper identifies lighting as a non-invasive method for the encouragement of the spontaneous development of leisure activities. The efficiency of the proposed lighting design model is tested through the scenario of light quality improvement. The outcome of the research is a set of guidelines that suggests effective solutions and an innovative approach to preserving the identity of community spaces in the contemporary context.

The proposed model presents novelty in the field of lighting design establishing a relationship between light quality, recreational dimension, and open public space in mass housing modernist settlements.

The possible application of a model for revitalisation of degradation of former community spaces in a contemporary context is a significant contribution in the field of architecture. Considering that adaptation of degraded spaces stimulates renewal and urban development, former community spaces should be revived as contemporary urban contents and engaged as promoters of modernist symbolic values designed while preserving inherited authenticity of architectural values of the context.

Comprehension of the built framework as symbolic values of the space that should be preserved is the key foundation in transformation of former community spaces into leisure spaces. Afterward, encouraging newly-formed activities by the improvement of lighting quality presents a tool that can support the recreational dimension in the contemporary moment.

The limitation of the presented research is reflected singular case study of one morphological type - the openformed residential settlement with skyscrapers. Future research may go in the direction of upgrading the proposed lighting design model for different morphological types of mass housing modernist settlements.

\section{Acknowledgements}

This research was funded by the Ministry of Education, Science and Technological Development of the Republic of Serbia, "Climate Change and its effects on the Environment - Monitoring, Adapting and Mitigating" [grant number III43007] and "Research and systematization of housing development in Serbia in the context of globalization and European integrations for the purpose of improving housing quality and standards" [grant number 36034].

\section{REFERENCES}

[1] Kalyukin, A., Borén, T., \& Byerley, A. (2015). The second generation of post-socialist change: Gorky Park and public space in Moscow. Urban Geography, 36(5), 674-695. https://doi.org/10.1080/02723638.2015.1020658

[2] Kristiánová, K. (2016). Post-Socialist Transformations of Green Open Spaces in Large Scale Socialist Housing Estates in Slovakia.Procedia Engineering, 161, 1863-1867. https://doi.org/10.1016/j.proeng.2016.08.715

[3] Djokić, V., Ristić Trajković, J., Furundžić, D., Krstić, V., \& Stojiljković, D. (2018). Urban garden as lived space: Informal gardening practices and dwelling culture in socialist and post-socialist Belgrade. Urban Forestry and Urban Greening, 30, 247-259. https://doi.org/10.1016/j.ufug.2017.05.014

[4] Hirt, S. (2008). Landscapes of Postmodernity: Changes in the Built Fabric of Belgrade and Sofia Since the End of
Socialism. Urban Geography, 29(8), 785-810. https://doi.org/10.2747/0272-3638.29.8.785

[5] Rakonjac, I. \& Jerković-Babović, B. (2019). Fluidity of open public space boundary. Proceedings of 13th International Conference FILUM, 379-390.

[6] Horkheimer, M. \& Adorno, T. W. (2006). The Culture Industry: Enlightenment as Mass Deception. Media and cultural studies. New York: Blackwell Publishing Ltd, 4172.

[7] Simmel, G. (2017), The metropolis and mental life. The City: Critical Essays in Human Geography. London: Routledge, 11-19. https://doi.org/10.1007/978-1-349-23708-1_4

[8] Milojević, M. (2009). Re-Conceptualization of the Idea of Neighborhood on Post-Socialist Belgrade. Serbian Architectural Journal, 1(1), 45-64.

[9] Lefebvre, H. (1991). The Production of Space. Cambridge, Oxford UK: Blackwell publishing.

[10] Nikezić, A., Ristić Trajković, J., \& Milovanović, A. (2021). Future housing identities: Designing in line with the contemporary sustainable urban lifestyle. Buildings, 11(1), 1-23. https://doi.org/10.3390/buildings 11010018

[11] Lefebvre, H. \& Moore, J. (2002). Critique of Everyday Life. London - New York: Verso.

[12] Frumkin, H., Bratman, G. N., Breslow, S. J., Cochran, B., Kahn, P. H., Lawler, J. J., Levin, P. S., Tandon, P. S., Varanasi, U., Wolf, K. L., \& Wood, S. A. (2017). Nature contact and human health: A research agenda. Environmental Health Perspectives, 125(7), 1-18. https://doi.org/10.1289/EHP1663

[13] Zlatanova, S., Yan, J., Wang, Y., Diakité, A., Isikdag, U., Sithole, G., \& Barton, J. (2020). Spaces in Spatial Science and Urban Applications - State of the Art Review. International Journal of Geo-Information, 9(1), 1-28. https://doi.org/10.3390/ijgi9010058

[14] Norwood, M. F., Lakhani, A., Fullagar, S., Maujean, A., Downes, M., Byrne, J., Stewart, A., Barber, B., \& Kendall, E. (2019). A narrative and systematic review of the behavioural, cognitive and emotional effects of passive nature exposure on young people: Evidence for prescribing change. Landscape and Urban Planning, 189, 71-79. https://doi.org/10.1016/j.landurbplan.2019.04.007

[15] Otto, S. \& Pensini, P. (2017). Nature-based environmental education of children: Environmental knowledge and connectedness to nature, together, are related to ecological behaviour. Global Environmental Change, 47, 88-94. https://doi.org/10.1016/j.gloenvcha.2017.09.009

[16] Hartig, T., Mitchell, R., de Vries, S., \& Frumkin, H. (2014). Nature and Health. Annual Review of Public Health, 35(1), 207-228. https://doi.org/10.1146/annurev-publhealth-032013-182443

[17] Di Salvo, S. (2014). Innovation in lighting for enhancing the appreciation and preservation of archaeological heritage. Journal of Cultural Heritage, 15(2), 209-212. https://doi.org/10.1016/j.culher.2013.03.001

[18] Djokić, L. (2007). Osvetljenje u arhitekturi. Zahtevi $i$ smernice za projektovanje [Lighting in Architecture. Requirements and Design Guidelines]. Belgrade: Faculty of Architecture, University of Belgrade.

[19] Vukmirović, M. (2013). The Importance and Role of Pedestrian Space Network in Generating the Competitive Identity of City. Doctoral dissertation. Belgrade University Faculty of Architecture, Serbia.

[20] Rakonjac, I. (2016).Phenomenon of the Open Public Space Boundary and the Emphasis of its Prominence by Lighting. Doctoral dissertation. Belgrade University - Faculty of Architecture, Serbia.

[21] Di Laura, D. L., Houser, K. W., Mistrick, R. G., \& Steffy, G. R. (2011). The lighting handbook. New York: Illuminating Engineering Society of North America.

[22] CIE Technical Committee 4-44. (2010). CIE 115 - Lighting 
of roads for motor and pedestrian traffic. 37.

[23] Publication BSIS. (2015). BSI Standards Publication Road lighting Part 2: Performance requirements, EN 132012:2015

[24] Rozman Cafuta, M. (2010). Public lighting in the communicative urban context. Informatologia, 43, 122-125

[25] Rakonjac, I., Rakonjac, I., Fotirić, N., Rajković, I., \& Gašić, M. (2016). Lighting Features Life Cycle Analysis for a Lighting System. Structural Integrity and Life, 16(2), 81-86

[26] Yin, R. K. (2018). Case study research and applications: Design and methods. Sixth Ed. SAGE Publications, Inc.

[27] Milojević, M. P., Maruna, M., \& Djordjević, A. (2019). Transition of Collective Land in Modernistic Residential Settings in New Belgrade, Serbia. Land, 8(11), 174. https://doi.org/10.3390/land8110174

[28] Zorić, A. \& Kostić, M. (2019). Spaces of peace - recreation as a method of programmatic transformation of military infrastructure. Proceedings of 13th International Conference FILUM, 267-278

[29] Kostić, M. (2000). Vodič kroz svet tehnike osvetljenja (The World of Lighting Technology Guide). Belgrade: MinelSchreder.

[30] Hebert, P., Sammons, T., Kang, M., \& Lee, H. J. (2013). Pedestrian and bike path illumination for safety and security: Empirical pre- and post-field studies by a university team. Urban Transport XIX, 130, 745-755. https://doi.org/10.2495/UT130601

[31] Słomiński, S. (2016). Identifying problems with luminaire luminance measurements for discomfort glare analysis. Lighting Research and Technology, 48(5), 573-588. https://doi.org/10.1177/1477153515596374

[32] Salata, F., Golasi, I., Falanga, G., Allegri, M., De Lieto Vollaro, E., Nardecchia, F., Pagliaro, F., Gugliermetti, F., \& De Lieto Vollaro, A. (2015). Maintenance and energy optimization of lighting systems for the improvement of historic buildings: A case study. Sustainability, 7(8), 1077010788. https://doi.org/10.3390/su70810770

[33] Kostic, M. \& Djokic, L. (2009). Recommendations for energy efficient and visually acceptable street lighting. Energy, 34, 1565-1572. https://doi.org/10.1016/j.energy.2009.06.056

[34] Kostic, A. M., Kremic, M. M., Djokic, L. S., \& Kostic, M. B. (2013). Light-emitting diodes in street and roadway lighting - A case study involving mesopic effects.Lighting Research and Technology, 45(2), 217-229. https://doi.org/10.1177/1477153512440771

[35] Beccali, M., Lo Brano, V., Bonomolo, M., Cicero, P., Corvisieri, G., Caruso, M., \& Gamberale, F. (2017). A multifunctional public lighting infrastructure, design and experimental test. Journal of Sustainable Development of Energy, Water and Environment Systems, 5(4), 608-625. https://doi.org/10.13044/j.sdewes.d5.0164
Vladan ĐOKIĆ, PhD, Full professor

Faculty of Architecture, Belgrade University,

Bulevar kralja Aleksandra 73/II, 11000 Belgrade, Serbia

E-mail: vdjokic@arh.bg.ac.rs

Milica P. MILOJEVIĆ, PhD, Assistant professor

Faculty of Architecture, Belgrade University,

Bulevar kralja Aleksandra 73/II, 11000 Belgrade, Serbia

E-mail:m.milojevic@arh.bg.ac.rs

Milena RAJIĆ, PhD, Assistant professor

Faculty of Mechanical Engineering, University of Niš,

Aleksandra Medvedova 14, 18000 Niš, Serbia

E-mail: milena.rajic@masfak.ni.ac.rs

\section{Contact information:}

Ivana RAKONJAC, PhD, Assistant professor

(Corresponding author)

Faculty of Architecture, Belgrade University,

Bulevar kralja Aleksandra 73/II, 11000 Belgrade, Serbia

E-mail: i.rakonjac@arh.bg.ac.rs

Ivan RAKONJAC, PhD, Assistant professor

Faculty of Security Studies, Belgrade University,

Gospodara Vučića Street 50, 11000 Belgrade, Serbia

E-mail: ivan.rakonjac@fb.bg.ac.rs

Ana ZORIĆ, PhD, Teaching assistant

Faculty of Architecture, Belgrade University,

Bulevar kralja Aleksandra 73/II, 11000 Belgrade, Serbia

E-mail: ana.zoric@arh.bg.ac.rs 